\title{
Correction to: Medial patellofemoral ligament reconstruction with and without trochleoplasty for patients with patella instability-correlation of trochlear dysplasia and patient outcome, classification and outcome measure in the past decade-a systematic review
}

\author{
Cheryl Marise Peilin $\operatorname{Tan}^{1}$ (1) $\cdot$ Yanan $\mathrm{Zhu}^{2,3} \cdot$ Liang Guo $^{2,3} \cdot$ Sir Young James Loh ${ }^{1}$
}

Published online: 28 June 2021

(c) Springer-Verlag France SAS, part of Springer Nature 2021

\section{Correction to: \\ European Journal of Orthopaedic Surgery \& \\ Traumatology \\ https://doi.org/10.1007/s00590-021-03030-z}

The original version of this article unfortunately contained a mistake. Author names was incorrect. Luming Shi is not an author.

Author group should be:
Cheryl Marise Peilin Tan · Yanan Zhu · Liang Guo · Sir Young James Loh.

The original article has been corrected.

Publisher's Note Springer Nature remains neutral with regard to jurisdictional claims in published maps and institutional affiliations.

The original article can be found online at https://doi.org/10.1007/ s00590-021-03030-z.

Cheryl Marise Peilin Tan

cherylfrancescatan@gmail.com

1 Department of Orthopaedic Surgery, Changi General

Hospital, 2 Simei Street 3, Singapore 529889, Singapore

2 Consortium for Clinical Research and Innovation, Singapore

Clinical Research Institute, Singapore, Singapore

3 Cochrane, Singapore 